\title{
The Importance of Continuing Medical Education During the COVID-19 Pandemic: the Global Educational Toxicology Uniting Project (GETUP)
}

\author{
Anselm Wong ${ }^{1,2}$ (D) $\cdot$ Rais Vohra ${ }^{3} \cdot$ Kathy Kopec $^{4} \cdot$ Nicholas Brooke $^{5,6} \cdot$ Andrew Stolbach $^{7}$
}

Received: 16 May 2020 / Revised: 19 May 2020 / Accepted: 20 May 2020 / Published online: 4 June 2020

(C) American College of Medical Toxicology 2020

Keywords Poisoning $\cdot$ Videoconference $\cdot$ Online $\cdot$ Curriculum

\section{Dear Editor,}

Although poisonings and overdoses have continued during the COVID-19 pandemic [1], social distancing practices and travel restrictions have resulted in canceling of in-person conferences and loss of continuing medical education opportunities for health care professionals. This loss may be felt more acutely in low- and middle-income areas without developed toxicology expertise that have traditionally relied upon travel for educational opportunities.

Professional societies, such as the American College of Medical Toxicology (ACMT) and the American Academy of Clinical Toxicology (AACT) have offered online toxicology resources to clinicians during this time. Prior to the pandemic, the Global Educational Toxicology Uniting Project (GETUP) was instituted to help improve connectivity and educational resources between clinicians in countries with

Supervising Editor: Mark B. Mycyk, MD

Anselm Wong

anselm.wong@austin.org.au

1 Victorian Poisons Information Centre and Austin Toxicology Service, Austin Hospital and University of Melbourne, Parkville, Victoria, Australia

2 Department of Medicine, School of Clinical Sciences at Monash Health, Monash University, Victoria, Australia

3 University of California San Francisco, Fresno Medical Center, Fresno, CA, USA

4 Carolinas Medical Center, Charlotte, NC, USA

5 Chemical Environmental Effects Centre for Radiation, Chemical and Environmental Hazards, Public Health England, Chilton, England

6 Ethiopian Poisons Center, Addis Ababa, Ethiopia

7 Department of Toxicology and Emergency, John Hopkins Hospital, Baltimore, MD, USA and without toxicology services. This was achieved through online medical toxicology-themed modules, videoconferencing, and lectures $[2,3]$.

Neumann et al. [4] recently described the roles a medical toxicologist could have during the COVID pandemic. In addition to these, contributing to continuing medical education activities remains another important role. GETUP has continued to enroll registrants in our free introductory clinical toxicology training program (www.acmt.net/GETUP). We have drawn participants from diverse professional backgrounds and geographic locations. From the start of the pandemic in December 2019 to the end of April 2020, there have been 60 registrants in 15 countries for the course. Participants include scientists, pharmacists, poison information specialists, medical students, residents, and physicians. For example, medical staff with toxicology placements in Oman and Qatar have used it during this time. We have provided GETUP training to poison centers in Ethiopia and Myanmar as part of International Health Regulations (IHR) strengthening initiatives led by Public Health England in conjunction with the UK National Poisons Information Service (NPIS) [5]. This will prove invaluable at supplementing training delivered by experts directly in country prior to the pandemic.

Also recently described in the Journal of Medical Toxicology was the Global Educational Toxicology toolKIT (GETKIT) [6]. This lecture series has been delivered in person to low- and middle-income countries without toxicology services and could be adapted for online teaching during this time. GETKIT has thus far received one request for access to this course material during this pandemic. In this era of renewed need for and interest in online education, videoconferencing platforms make it much easier to share this set of peer-reviewed presentations, deliver lectures to new learners, and forge new connections among the global toxicology and critical care communities. 
As the pandemic continues, the importance of accessible medical education to support clinicians who are managing poisoned patients worldwide is necessary. In this troubling time where everyone is affected in one way or another, we need to strive to continue educational initiatives for poison management and prevention. Stay safe, stay connected, and keep learning.

Funding Information AW is supported by a NHMRC Research Fellowship ID 1159907.

\section{Compliance with Ethical Standards}

Conflict of Interest None.

\section{References}

1. Chang A, Schnall AH, Law R, Bronstein AC, Marraffa JM, Spiller $\mathrm{HA}$, et al. Cleaning and disinfectant chemical exposures and temporal associations with COVID-19 - National Poison Data System,
United States, January 1, 2020-March 31, 2020. MMWR Morb Mortal Wkly Rep. 2020;69(16):496-8.

2. Wong A, Vohra R, Ruha AM, Koutsogiannis Z, Graeme K, Dargan PI, et al. The global educational toxicology uniting project (GETUP): an analysis of the first year of a novel toxicology education project. $\mathrm{J}$ Med Toxicol. 2015;11(3):295-300.

3. Wong A, Vohra R, Dawson AH, Stolbach A. Impact of online toxicology training on health professionals: the global educational toxicology uniting project (GETUP). Clin Toxicol (Phila). 2017;55(9): 981-5.

4. Neumann NR, Chai PR, Wood DM, Greller HA, Mycyk MB. Medical toxicology and COVID-19: our role in a pandemic. J Med Toxicol. 2020;16(3). https://doi.org/10.1007/s13181-020-00778-4.

5. WHO. International Health Regulations (second edition). Geneva: World Health Organisation; 2008.

6. Kopec KT, Vohra R, Santos C, Kazzi Z, Wong A. The global educational toxicology toolkit (GETKIT): a 1-day course for teaching poisoning essentials in low- and middle-income countries (LMIC): course development and pilot data analysis. J Med Toxicol. 2020;16(3). https://doi.org/10.1007/s13181-019-00745-8.

Publisher's Note Springer Nature remains neutral with regard to jurisdictional claims in published maps and institutional affiliations. 